\title{
Auditory Verbal Therapy
}

\section{Jaspal Chowdhry}

Habilitation Manager, South Asia Cochlear Ltd.

Correspondence: Jaspal Chowdhry, Habilitation Manager, South Asia Cochlear Ltd., e-mail: Jchowdhry@cochlear.com

\begin{abstract}
Hearing impairment leaves a wide ranging impact on young children and their parents. Early identification and intervention is crucial to a child's development of speech and language. Today, with advanced technology development, we can work from a developmental prospective rather than remedial and corrective. This approach is called auditory verbal therapy (AVT). The aim of this approach is to develop spoken language. So that children can become independent, participating and contributing citizens of mainstream society. Parents play a significance role in individualized auditory verbal therapy as parents and family members are the best people to develop spoken language in the natural listening environment at home. Auditory verbal therapy is an applied science. Objectively measured goals in the areas of audition, speech, language and cognition are set and achieved in individualized sessions with parents as partners in therapy.

Keywords: Hearing impairment, invisible disability, residual hearing, hearing device, auditory verbal therapy, caregivers, early intervention, developmental, auditory habilitation, diagnostic therapy, auditory potential, preoperative habilitation, listening environment.
\end{abstract}

\section{INTRODUCTION}

Hearing impairment is called the invisible disability but it impacts on every facet of life for a child and their family. Considering the wide ranging impacts of hearing impairment on young children and their parents, the earlier the hearing loss can be diagnosed the better. Early identification and intervention during the critical early learning years, has been proven to be crucial to the child's development of speech and language.

Today, majority of children with hearing impairment have the potential to access all the sounds of spoken language through listening alone, because of new technology developments. "What has happened in the field of hearing

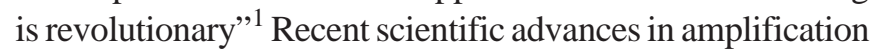
and cochlear implant technology can provide great potential listening opportunities to children with profound hearing loss. Because of these improvements in hearing devices, more and more babies and children with hearing loss, have access to sounds as never before. Never before has there been such potential for children who are born deaf or hard of hearing or who acquire deafness in early childhood. Most of these children can learn to listen to their own voices, listen to the voices of others and listen to the sounds of life. ${ }^{2}$ With this new population of babies and young children, we can work from a developmental and preventive prospective rather than from a remedial and corrective one. "AVT is natural companion of such technology". 4

Crucial to effective early intervention is effective audio logic management. Once a child's hearing loss is identified, they need to be fitted with appropriate hearing aids as soon as possible so that they can access their residual hearing with the right hearing device. Then the child needs to learn to listen and make use of the hearing signals that they receive. ${ }^{6}$ You can not just put on hearing aids on a hearing impaired child and expect him to hear and speak. Simply providing hearing devices does not mean the sound will be perceived or interpreted. The child needs to learn to listen and understand through these devices. ${ }^{7}$ They need to learn that sound has meaning and is related to all that is going on around them. It is important to remember that access to sound does not automatically mean that speech and language will develop. ${ }^{8}$ Appropriate teaching is essential. "Technology and medical devices only give children access to hearing. Whether the children learn to use this hearing depends on the therapy that they receive, once they have been given this hearing potential” Judith Simser.

\section{THE MISSION}

The mission of the auditory verbal approach is to help these children to use their hearing and listening potential to communicate through spoken language. ${ }^{3}$

\section{DEFINITION OF AVT}

Auditory verbal therapy provides systematic instructions to hearing impaired children and their parents.

Auditory: Children who are deaf learn how to listen.

Verbal: Children who are deaf learn how to talk.

Therapy: Parent/caregiver attends one to one lessons with their child and learns how to teach their children in everyday situations. 
Auditory verbal therapy (AVT) is an early intervention approach for the children who are deaf or hard of hearing and are fitted with hearing devices in an early age. ${ }^{11,13}$ It is individualized therapy on one to one basis in a listening environment. The goals are set in four areas of development such as; audition language, speech and cognition. Parents are partners in this program focused to develop spoken language communication. AVT emphasises the development of listening and language through natural play, singing, daily routines as well as structured therapy activities. AVT focuses on education, guidance, family support and "rigorous application of techniques, strategies conditions and procedures that promote optimal acquisition of spoken language through listening”. 5

\section{PREREQUISITES OF AVT}

- Early detection

- Appropriate use of hearing device

- One on one intervention with full parent involvement

- Absence of signs and speech reading training

- Integration with hearing peers

- On going diagnostic therapy.

\section{THE GOALS OF AVT}

The goal of auditory verbal practice is that children with hearing impairment can grow up in regular learning and living environments that enable them to become independent, participating and contributing citizens in mainstream society. ${ }^{14}$ The goals of AVT are for children to learn to listen and talk to engage in meaningful conversation, to be assimilated into regular school programs and to have

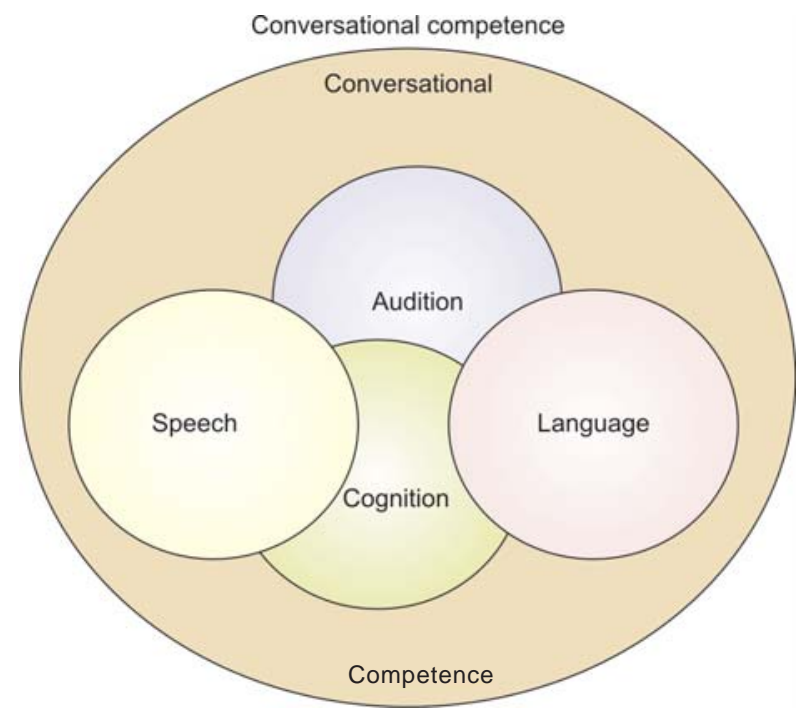

educational, social and vocational choices throughout life. ${ }^{15}$ The goal of Auditory Verbal Therapy is to develop conversation and competency in children.

\section{SIGNIFICANCE OF AVT}

Developing spoken language through listening requires an ongoing commitment and dedication by all involved. Parents/ caregivers are the key players in their child's development. It is the parents who provide the wealth of spoken language interaction on a one to one basis throughout the child's waking hours. ${ }^{16}$ They need to develop an understanding of the different stages of Listening, Language, Speech and Cognition. They need to know, understand and learn how to develop listening skills through meaningful everyday interaction with their child. This is the role of an AVT therapist to help, guide and coach them in this area. When a child is diagnosed with hearing impairment, parents will seek a program to suit their goals and needs. When their child is fitted with advance hearing devices, Auditory Habilitation program is more logical to be followed. A family centered auditory habilitation program has focus primarily on providing parents and family members with skills, knowledge and confidence to provide the best possible auditory language learning environment for their child through participation and practice. Therapist provides this participation and practice to parents in customized one to one auditory verbal sessions with their child. Such a program is based on ongoing assessment of the child's individual needs. ${ }^{17}$ Parents learn about the different stages of Listening, Language, Speech and Cognition. They also gain the skills to use appropriate spoken language in play and other daily activities. "They learn to capitalize on the many opportunities for stimulating listening and language learning that arise in natural interaction in the home (Listen, Learn and Talk, Cochlear Hear now and Always). ${ }^{18}$

AVT can provide opportunities to many children who are deaf or hard of hearing to learn to listen to process spoken language and to talk. AVT promotes early detection and diagnoses of hearing impairment, consistent use of hearing device, individualized therapy and learning environment where listening and spoken language are the expected mode of communication. ${ }^{13}$

AVT helps parents to develop skills to become the primary models for speech and language development. AVT encourages the child to realize his auditory potential to learn spoken language communication. AVT is individualized and 
tailored to the specific needs of the child and the family. It is not a combination of formal exercises and is not conducted in a group. The child's auditory abilities develop because emphasis is placed on listening throughout all the child's waking hours, "so that listening becomes an integral part of his/her personality ${ }^{3}$ (Cole et al, 2005). The role of the family in early intervention is essential to establish the child's preverbal skills, and for the parents and family to accept the hearing impairment. The parents become confident in their role as the primary language model and facilitator. All these necessary elements of effective early intervention are found in AVT. Learning to listen occurs only when children seek to extract meaning from the acoustic events surrounding them all day and everyday. ${ }^{10}$

Research has shown that babies learn the basics of their native language by the age of six months, long before they utter their first words. During their first twelve months, they are listening to what is going on around them and interacting with their parents and family. By the age of three, most typically developing children have basic communicative competencies in all areas. "A baby who is deprived of appropriate language stimulation during the first three years of life, can never attain optimal language function” (Baltimore, 1996).

Auditory verbal therapy is most effective habilitation device for children with cochlear implant because it places emphasis on audition alone. Particularly for congenitally deaf children who have no experience of sound, it is essential that there be a strong focus on audition and a conscious reduction in the visual input. Once hearing impaired children receive auditory information, they need to learn how to use it. "If appropriate auditory and linguistic experience is provided to most children who are deaf or hard of hearing from an early age, then cognitive and listening functioning can be expected to follow the normal course of development”. ${ }^{1}$ Auditory habilitation helps hearing impaired children to overcome their handicap and become members of mainstream society.

\section{STRUCTURE OF AVT}

Whenever, the child learns to perform any task in a structured activity or game, the task must then be integrated into real life situations in order to be functional for him or her. Parents/ caregivers and family members are the best people to develop spoken language through listening in the home, in the natural environment. AVT encourages and follows natural language and speech development through play and active involvement in every day situations. Listening becomes a way of life ${ }^{9}$ (Estabrooks and Samson, 1992).

AVT can be taken in a hospital, clinic, as private practice and in a school. Auditory verbal therapist takes sessions once or twice a week, for an hour with goals based on the natural patterns of development of children with typical hearing. In each AVT session, the therapist provides coaching and guidance for the parents and diagnostic assessment of the progress of the child. The therapist uses strategies and techniques to maximise the auditory potential of the child. Auditory verbal therapy is considered diagnostic because it is the process of ongoing examination of the individual child's overall progress. AVT is diagnostic as it attempts to explain or establish the functional level of the development of the child who is deaf or hard of hearing in line with their hearing peers.

\section{PREOPERATIVE HABILITATION}

Preoperative habilitation is vital preparation for the continuing auditory verbal habilitation after the surgery and switch on. After switch on, the postoperative habilitation begins. The electronic sound the child hears through the cochlear implant is different from any acoustic sound the child may have heard through their hearing aids.

\section{VARIABLES AFFECTING OUTCOMES OF AVT}

1. Age at diagnosis and implantation

2. Audiological management

3. Emotional state of the family

4. Child's intelligence and development

5. Skills of the therapist

6 Family participation.

\section{CONCLUSION}

Scientific advances in hearing technology and recent trends in family oriented therapy and education has provided great opportunities for children who are deaf or hard of hearing to acquire intelligible spoken language. Auditory verbal therapy, as an applied science with objectively measured goals, guides and supports parents in helping their child learn to talk by listening to learn. Consequently, their child can grow up with abundant choices in life. ${ }^{3,12}$ 


\section{REFERENCES}

1. Elizabeth B Cole, Carol Flexer. Children with Hearing Loss. Developing Listening and Talking, 2008.

2. Talk and Sing songs for Hearing Impaired Children by Warren Estabrooks, June 2000.

3. Who Need Helping to Talk by Warren Estabrooks, June 2006.

4. Therapy by Warren Estabrooks and Rhonda Sogwartz, 2007.

5. Cochlear Implant for Kids, Warren Estabrooks, 2004.

6. Listen to This, Volume 1(2004) by Warren Estabrooks, 2004.

7. Auditory Verbal Therapy for Parents and Professionals by Warren Estabrooks, 2004.

8. Auditory Verbap Approach by Doreen Poolack, 1977.

9. Educational Audiology for the Limited Hearing Infant by Doreen Pollack, 1985
10. Foundations of Spoken Language for Hearing Impaired by Daniel Ling, 1986.

11. Cochlear Ltd. Listen, Learn and Talk, 2003.

12. Estabrooks W. Auditory-Verbal Therapy and Practice, 2006.

13. Pollack D, Caleffe-Schenck, N Goldberg D. Educational Audiology for the Limited Hearing Infant and Preschooler, 1997.

14. An Introduction to Spoken Language Development, Allyn and Bacon, 2005.

15. Speech and Hearing Impaired Child: Theory and Practice, Ling D, 2002.

16. Parent-Infant Communication, Schuyler V, Sowers, 1998.

17. 50 FAQs about AVT, Estabrooks W, 2001.

18. Foundations of Spoken Language for Hearing Impaired Children, Ling D, 1990. 